\title{
Analysis of Football Teaching Reform and Football Culture Dissemination at Colleges and Universities
}

\author{
Weijun Zhang \\ Research Institute for Higher Education, Xianyang Normal University, 712000
}

\section{Keywords: Football teaching; Reform; Footfall culture}

\begin{abstract}
This paper briefly analyzes the present situation of college football teaching in China, puts forward the idea to reform college football teaching and examine and summarize traditional physical education from the perspective of cultural communication. Based on the teaching practice and combined with the characteristics of football, the teaching improvement methods and steps proposed to represent new breakthroughs and new advances in related direction research not only have a certain guiding role for the improvement of the teaching quality of college football courses, but also provide guidance for the reform of other projects.
\end{abstract}

Football is one of the important contents of physical education in ordinary colleges and universities. For many years, under the national advocacy and the joint efforts of all walks of life, football teaching has been popularized in universities. The development of football teaching and football in colleges and universities has played a very active role in enriching students' cultural life and training students' physique. Football originated in China. Ancient Chinese crickets are the prototype of football. Although the current development level of football is relatively low in China, football has a wide social base in China, and is particularly popular among young students.

Football is the most magical sport in the world today and is claimed to be the world's largest sport, which is is by no means unrivaled. According to incomplete statistics, there are about 800,000 teams that regularly participate in football competitions in the world. The number of registered athletes is about 40 million, of which there are roughly 100,000 professional athletes. The number of football fans is overwhelming. During the influential events such as the World Cup and the European Cup, the cities and villages in the countries concerned can almost reach the level of all-or-nothing.

The number of Chinese people who love football is by no means in the minority, but it is a frequently puzzling question as why is the overall level of football development lagging behind. Some people say that Chinese people are good at going it alone and are not good at collective sports. Some people say that Chinese people's physique is obviously at a disadvantage compared with Westerners. Some people start from the organization of football sports events and point out the shortcomings. For the time being not to say what exactly is the accuracy of these contents, this research alone shows everyone's concern about and expectations for football.

\section{Current Status of College Football Teaching in China}

After years of development of college football teaching in China, great progress has been made in terms of both hardware and course design, but while noticing the achievements, we should also directly face the problems in teaching. As a college sports teaching worker, the author has been paying attention to the development of football in Chinese universities for a long time, and has carried out in-depth thinking and careful analysis on the theoretical research results of related directions. In the author's opinions, the football teaching in China's higher education stage has the following problems:

\section{The Teaching Goal is Unclear}

The unclear goal in the teaching process is the biggest bottleneck that hinders the development of college football teaching. The teaching of college football in China is basically based on the classroom. Through the implementation of the teaching process, the overall quality of the students' mind and body is improved. The students are encouraged to establish the concept of sports lifelong education, cultivate their good habits, and shape their complete personality. However, in the 
implementation of teaching, teachers must first complete the basic teaching tasks in the classroom. This kind of teaching task is often rigid, step-by-step, giving the teacher little room for personal potential. This has led to the fact that on the one hand, the majority of teachers in teaching should try their best to teach students according to their aptitude and make use of the situation. On the other hand, they should take into account the progress of the curriculum. For a teacher, this contradiction is difficult to solve and is often in a dilemma. Clear teaching goals should be longterm and consistent throughout teaching, playing a decisive guiding role. Meanwhile, it should have a certain degree of flexibility. From a global point of view, it is a process of dispersed contents but one unified soul. However, in the current college football teaching, we overemphasize the importance of the teaching node and neglect the longevity as the basis of teaching goals.

\section{Lack of Training of Students' Awareness of Competition}

As a competitive sport, football should have its fundamental attribute of being competitive. Only by fully emphasizing the competitive characteristics of football, can we cultivate students' sense of cooperation and team awareness based on this. China is a state of etiquette. Etiquette culture penetrates into all aspects of social life and even dominates the teaching philosophy of competitive sports. Friendship first, competition second; slogans such as compliance, unity and respect are filled with teaching and competition. It is true that physical fitness is the most basic benefit of sports, but the sense of competition is also an important part of a complete personality. Awareness of competition not only affects individuals, but also has a decisive position on a country and a nation. The lack of cultivating students' competitive awareness in college football teaching is a representative and universal issue.

\section{Many Colleges and Universities Do not Pay Enough Attention to Football Teaching}

The source of funding for China's higher education system is mainly in the form of national allocation. Local governments have certain financial support for higher education based on their own abilities, but they do not occupy a dominant position. The funds received by different universities and different majors may be greatly different each year. Schools will inevitably tend to use funds according to their own development needs and key disciplines. After all these years of development, college football teaching can basically satisfy the teaching needs by accumulating hardware conditions, but the expansion of teaching conditions and improvement of teaching environment under capital investment are not satisfactory. In most colleges and universities, the standard for football teaching is basically the football field and sports equipment. The high-end teaching facilities such as tactical explanation classes and audio/video playrooms are basically not equipped. When there is wind or it rains, students either make their own arrangements or change to other indoor sports. This reflects from a side that colleges and universities do not pay enough attention to football teaching as a whole.

\section{Lack of Professional Teaching Team}

The lack of professional teachers is an important issue that restricts the development of college football teaching. Many people's understanding of football teaching has remained at a very shallow level. It is believed that graduates of any sports-related major can teach this course. In their view, there is no technical content in football teaching. They can move their legs, move their feet, and can deal with students running around the playground. There are not a few people who hold such prejudices against football teaching. Among all majors in the university, the opportunities for teachers of sports related majors to study and exchange are rare compared to other majors. Many teachers who have been engaged in many years of physical education have never received any retraining. Immutable teaching thinking and rigid old teaching concepts exist in the minds of many teachers.

\section{Research of Methods to Reform College Football Teaching}

In recent years, many people of insight in society have seen many shortcomings in college football teaching. They have carried out in-depth thinking and research and bold attempts at both theoretical and practical levels, and have achieved significant results. The reform of college football teaching is a systematic project. There are many links involved in the implementation and the task is heavy. 
However, we cannot retreat from difficulties. We should view the relevant reform measures based on our sense of mission and the sense of responsibility. Under the background of the transformation and reform of college education and teaching, the reform of football teaching is in full swing. Based the author's own teaching practice experience, the author combines theoretical and practical research results in the relevant direction, and concludes that college football teaching reform should focus on the following aspects:

\section{Innovate the Teaching Concept}

Thought guides acts. The idea of innovative teaching should bear the brunt of the reform of college football teaching. In the traditional teaching philosophy, the teacher occupies a dominant position. The relationship between the student and the teacher is basically a subordinate relationship. Students do what the teacher asks them to do. In the new teaching concept, the dominant position of the students should be strengthened. They should establish a people-centered awareness in education and education, be concerned with the actual needs of students, pay attention to differences in students' interests and hobbies, and inspire students' interest in guidance and teaching.

\section{Innovate the Teaching Means}

With the continuous advancement of information technology, traditional teaching methods have obviously not adapted to the needs of modern educational and teaching development. How do traditional sports teaching methods innovate? This problem has long plagued the majority of physical education teachers. The reason why such a situation is formed is that physical education teachers are generally unfamiliar with information-based design methods such as computers, communications, and software. Even though they have good ideas in education and teaching, they are often less likely to be designed and implemented. In the end, they have nothing left to do. Second, the cost of sports teaching aids and equipment is relatively high, and the school often considers it over and over again and eventually gives it up. The reform of physical education teaching methods is not in a situation that is incurable. First, schools can promote the joint development of sports colleges and colleges of computers and software, relying on their own strengths to solve practical needs in teaching; Secondly, in the equipment purchase, we can take the socialization road. Equipment is to be open to the public while protecting education and teaching. As long as the management is properly maintained, it is not difficult to balance the income and expenditure, and sometimes there are still many savings.

\section{Cultivate Students' Awareness of Competition}

The complete character of a person consists of many factors. The sense of competition is the basic element of character that a person should possess. The establishment of a sense of competition is not to make students compete with others everywhere, but to combine the characteristics of sports to allow students to learn how to achieve their goals. This is the basic appeal of competitive sports in terms of personnel training and education and teaching philosophy. Competition and cooperation are not in themselves contradictory, but they have different focuses when applied to different situations.

\section{Strengthen the Construction of College Football Teaching Faculty}

Workers must first sharpen his tools for good things. The main organizers and implementers of college football teaching are teachers. Even the best education and teaching concepts must be implemented through teachers' teaching. Therefore, strengthening the construction of college football teachers is a basic and pioneering task. Schools should create good conditions for exchanges and learning for teachers, so that teachers can broaden their horizons in exchange and study and improve their performance. On-job retraining is also an important means of capacity improvement. The job retraining should be held on a regular basis. The training content should be fully prepared and closely follow the actual teaching. The department in charge of education and teaching during the implementation of the organization shall follow up in a comprehensive way, and promptly absorb the opinions and suggestions put forward by the teachers in the training. After summarizing, relevant departments shall carefully take measures for improvement. 


\section{The Mission of Spreading the Football Culture in the Reform of College Football Teaching}

Football culture is a broad concept. Football culture mainly refers to the material and spiritual symbol systems formed by using football as a carrier. It mainly includes sports activities centered on football competitions, refereeing behaviors, advertising and economic behaviors, and government actions.

Football culture is both a simple culture and a fashion culture. In football, both athletes get rid of the shackles of race and the rich and the poor, and use their strength to prove their level of exercise within the scope of specific rules. The principle of equivalence in football allows both sides of the game to be on the same starting line. The two parties share the same rules in front of each other, which promotes the spirit of equal and unbiased sports. In each competition, the audience is spiritually baptized. Football culture is also a happy culture. The football field is relatively open. Both athletes ride the battlefield and fully enjoy the exercise and excitement brought about by the exercise load. Whether it is the interplay between team members or the individual's galloping breakthrough, it is the perfect combination and release of wisdom and physical strength.

Sports and culture are closely related. As we mentioned earlier, the influence of Chinese etiquette culture on sports is profound and long-lasting. In order to achieve long-term development, any sport must find its destination in culture. At the same time, the support of culture can give sports vitality. The current low level of Chinese football competition should be largely attributed to the backwardness of the development level of Chinese football culture. When it comes to Chinese football culture, the first thing that comes to mind in everyone's mind is mainly the use of fake ball games, put on air, and fights. The sluggishness and negativeness of Chinese football culture has had a full range of negative effects on the development of Chinese football. Many scholars believe that the key to revitalizing Chinese football should begin with reshaping Chinese football culture. Accumulation and formation of culture is not instant or a step away. Fortunately, the elimination and restructuring of football culture has risen to the national level.

A very important mission in the reform of college football teaching is to assume the function of football culture communication. The reason why colleges and universities are used as the carrier of soccer culture dissemination is, first of all, because colleges and universities are the most frontier positions in our country's cultural communication system. Throughout the cultural changes in our country's history, higher education institutions always act as vanguards; Second, university students have a high level of general cultural quality and strong ability to accept. They have a strong ability to identify new things. Football culture has a profound mass base among students, which provides favorable conditions for the spread of football culture. Finally, colleges and universities have powerful scientific research methods and provide a broad channel for the dissemination of cultural information.

\section{Conclusion}

Colleges and universities are the main positions for talent cultivation and output in China. With the development of the society and the progress of the times, the country's quality requirements for the output of higher education professionals have been continuously improved. The reform and innovation of the teaching model of colleges and universities is not only the need for the survival and development of schools, but also the inherent requirement for the development of education and teaching. Football teaching in colleges and universities bears important social functions and personnel training functions in the transition of education. As college football educators, we must not only see the horizontal gap between our colleges and universities, but also the intrinsic cause of the development of football. Based on our own standpoint, we should endeavor to explore and have bold practice to make our due contribution to the revitalization of China's football cause and the cultivation of football talents.sd 


\section{References}

[1] YAN Xianliang. Discussion on the Teaching Reform of Football at Ordinary College PE Classes [J]. Examination Weekly. 2007 (42).

[2] SHA Jin. Comprehensive Development of Sports at School in the Perspective [D]. Northeast Normal University, 2012.

[3] SUN Yue. Research on the Development of Sports Management in China [D]. Beijing Sport University, 2012.

[4] WANG Xianghong. Study on the Optimization and Integration of Competitive Sports Talents Training System in China [D]. Northeast Normal University,2011.

[5] LIU Yayun. Research on the Training Mode of Chinese Competitive Sports Talents during Social Transformation [D]. Hunan Normal University, 2011.

[6] ZHANG Xiaojing. Restrictive Factors and Improvement Strategies in the Development of College Football Teaching [J]. Journal of Chifeng University.2017

[7] CAO Hong. The Status Quo of College Football Development and Countermeasures [J]. Sports World, 2017 